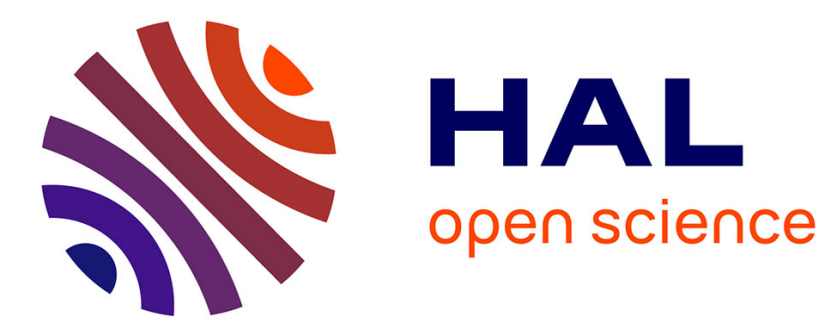

\title{
Complementary assays for monitoring susceptibility of varicella-zoster virus resistance to antivirals
}

\author{
Marine Perrier, Nathalie Désiré, Claire Deback, Henri Agut, David
}

Boutolleau, Sonia Burrel

\section{- To cite this version:}

Marine Perrier, Nathalie Désiré, Claire Deback, Henri Agut, David Boutolleau, et al.. Complementary assays for monitoring susceptibility of varicella-zoster virus resistance to antivirals. Journal of Virological Methods, 2016, 233, pp.10-14. 10.1016/j.jviromet.2016.03.006 . hal-01297442

\section{HAL Id: hal-01297442 \\ https://hal.sorbonne-universite.fr/hal-01297442}

Submitted on 4 Apr 2016

HAL is a multi-disciplinary open access archive for the deposit and dissemination of scientific research documents, whether they are published or not. The documents may come from teaching and research institutions in France or abroad, or from public or private research centers.
L'archive ouverte pluridisciplinaire HAL, est destinée au dépôt et à la diffusion de documents scientifiques de niveau recherche, publiés ou non, émanant des établissements d'enseignement et de recherche français ou étrangers, des laboratoires publics ou privés. 


\title{
Complementary assays for monitoring susceptibility of varicella-zoster virus resistance to antivirals
}

\author{
Marine Perrier ${ }^{\mathrm{a}, \mathrm{b}}$, Nathalie Désiré ${ }^{\mathrm{c}, \mathrm{d}}$, Claire Deback ${ }^{\mathrm{e}, \mathrm{f}}$, Henri Agut ${ }^{\mathrm{c}, \mathrm{g}}$, \\ David Boutolleau $^{\mathrm{c}, \mathrm{g}}$, Sonia Burrel ${ }^{\mathrm{c}, \mathrm{g}^{*}}$.
}

a AP-HP, Hôpitaux Universitaires Bichat-Claude Bernard, Service de Virologie, Paris, France

${ }^{\mathrm{b}}$ Université Paris Diderot, IAME, INSERM UMR 1137, Sorbonne Paris Cité, Paris, France ${ }^{c}$ AP-HP, Hôpitaux Universitaires Pitié-Salpêtrière - Charles Foix, Service de Virologie, Paris, France

d Sorbonne Universités, UPMC Univ Paris 06, INSERM UMR_S 1136, Institut Pierre Louis d'Epidémiologie et de Santé Publique, Paris, France

e AP-HP, Hôpital Paul Brousse, Service de Virologie, Villejuif, France

f Université Paris-Sud/Paris-Saclay, INSERM UMR 996, Inflammation, Chemokines and Immunopathology, Clamart, France.

g Sorbonne Universités, UPMC Univ Paris 06, CR7, Centre d'Immunologie et des Maladies Infectieuses (CIMI-Paris), INSERM U1135, Paris, France

\section{Corresponding author:}

Dr Sonia BURREL

Service de Virologie, Bâtiment CERVI, Groupe Hospitalier Pitié-Salpêtrière, 83 boulevard de l’Hôpital, F-75013, Paris, France

Telephone number: + 33142177402

Fax number: + 33142177411

Email address: sonia.burrel@aphp.fr 


\section{Highlights:}

- Useful methods for the monitoring of VZV resistance to antivirals

- Novel natural polymorphisms of VZV TK and DNA polymerase

- Nonradioactive evaluation of in vitro phosphorylation activity of VZV TK

\section{Summary}

The emergence of varicella-zoster virus (VZV) resistance to current antivirals as acyclovir (ACV) constitutes a hindrance to antiviral treatment effectiveness of VZV infections, especially in immunocompromised patients. The molecular mechanisms of VZV resistance reported so far rely on the presence of mutations within thymidine kinase (TK, ORF36) and DNA polymerase (ORF28) viral genes. The aim of this work was to develop reliable and complementary diagnostic methods to detect VZV antiviral resistance: (i) a genotypic assay based on TK and DNA polymerase genes sequencing, (ii) a plaque reduction assay to determine antiviral 50\% effective concentrations, and (iii) a functional assay to evaluate in vitro phosphorylation activity of recombinant TKs. As a whole, this study included the analysis of $21 \mathrm{VZV}$ clinical isolates and 62 biological samples from patients experiencing VZV infection. Genetic analysis revealed 3 and 9 new amino acid changes that have not been previously described within the highly conserved TK and DNA polymerase, respectively. Then, VZV isolates bearing newly identified mutations considered as natural polymorphisms were characterized as susceptible to ACV using plaque-reduction assay in MeWo cells. In parallel, the impact of TK changes on ACV phosphorylation activity was examined using a nonradioactive in vitro enzymatic assay.

Keywords: varicella-zoster virus; natural polymorphism; antiviral resistance testing; acyclovir phosphorylation activity 
Varicella-zoster virus (VZV) is a common herpesvirus that is usually known to be responsible for benign varicella and for localized recurrent zoster lesions. VZV infections are associated with significant morbidity and mortality among immunocompromised individuals, especially in HIV-infected patients or in hematopoietic stem cell transplant recipients, because of either disseminated infections or chronic reactivations (Morfin et al., 1999). Acyclovir (ACV) constitutes the first-line therapy for management of VZV infections. ACV, after activation by primophosphorylation by the viral thymidine kinase (TK, encoded by open reading frame 36 [ORF36]), targets the viral DNA polymerase (ORF28) and disrupts the viral genome replication by a chain termination mechanism. Foscarnet (FOS) constitutes an alternative drug that is effective without the phosphorylation by viral TK and that directly inhibits the viral DNA polymerase (Andrei and Snoeck, 2013; Piret and Boivin, 2014). According to these mechanisms of action, viral mutations conferring resistance to anti-VZV drugs have been mapped both in ORF36 and ORF28. However ACV-resistance of VZV strains is mostly mediated by mutations within TK (Piret and Boivin, 2014). To date, few studies have described extensively the natural polymorphism of VZV TK and DNA polymerase and have identified mutations conferring VZV resistance to antivirals (Andrei et al., 2012; Brunnemann et al., 2015; Fillet et al., 1998; Morfin et al., 1999; Sauerbrei et al., 2011; Talarico et al., 1993; Visse et al., 1998). However, the precise interpretation of genotypic resistance assays, based on the identification of specific mutations in TK and DNA polymerase, requires the clear distinction between natural polymorphisms and mutations conferring antiviral resistance. Classically, the undeniable assessment of a presumed resistance mutation is performed by testing recombinant viral mutants, generated by marker transfer experiments or bacterial artificial chromosome (BAC) machinery, for drug susceptibility using a standardized phenotypic assay (Brunnemann et al., 2015). For VZV, a trustworthy alternative strategy for 
the evaluation of the contribution of VZV TK mutations in antiviral resistance is to assess the in vitro enzymatic activity of mutant TKs. To date, few methods to study in vitro functional activity of VZV TK have been reported: radioactive assays (Ng et al., 2001; Suzutani et al., 2000) and a bacterial colony reduction assay based on restoration of TK-deficient bacteria sensitivity producing functional VZV TK (Sahli et al., 2000). Regarding the herpes simplex virus (HSV), a virus also belonging to the Alphaherpesvirinae subfamily, many methods, either radioactive or non-radioactive ones, have been described for the evaluation of TK phosphorylation activity: radioactive assays based on the use of ${ }^{3} \mathrm{H}$-labeled thymidine as a substrate or non-radioactive assays indirectly measuring HSV TK activity (Burrel et al., 2012; Frobert et al., 2007, 2005; Malartre et al., 2012; Sauerbrei et al., 2013; Suzutani et al., 2000). The aim of this work was to develop reliable and complementary systems for detection and confirmation of VZV antiviral resistance viz.: (i) a genotypic assay based on TK and DNA polymerase gene sequencing, (ii) a plaque reduction assay (PRA) to determine antiviral $50 \%$ effective concentrations $\left(\mathrm{EC}_{50}\right)$, and (iii) a functional assay to evaluate in vitro phosphorylation activity of recombinant TKs.

VZV laboratory strain Oka, $21 \mathrm{VZV}$ clinical isolates, and 62 clinical samples were included in the present study. Samples were recovered from distinct patients (median age, 52 years; range, 1-89 and comprising 47 men and 36 women) hospitalized at La Pitié SalpêtrièreCharles Foix University Hospital and experiencing VZV infection, mainly zoster lesions. None of the patients received prior long-term treatment with anti-VZV therapy, at most occasional ACV therapy for treating HSV infections. VZV isolates were obtained from clinical samples by propagation in human fibroblasts (MRC-5) (Harper, 2000).

For genotypic assay, viral DNA was extracted from clinical samples and viral stocks (clinical isolates and laboratory strain Oka) with the MagNA Pure Compact Instrument (Roche 
Diagnostics, Meylan, France), according to the manufacturer's instructions, and stored at $20^{\circ} \mathrm{C}$ for further analysis. TK (ORF36) and DNA polymerase (ORF28) full-length gene amplification (first-round and second-round PCR annealing primers temperature: $52^{\circ} \mathrm{C}$ and $59^{\circ} \mathrm{C}$ for $\mathrm{ORF} 36$ and $\mathrm{ORF} 28$, respectively) and sequencing were performed using primers listed in Table 1, with the proofreading enzyme Expand High Fidelity (Roche Diagnostics), according to previously described procedures (Burrel et al., 2010). In order to minimize possible PCR artefacts, all sequences were performed twice on both DNA strands. Nucleotide and amino acid sequences were compared with those of VZV reference strain Dumas (GenBank accession number X04370) (Davison and Scott, 1986). All sequences determined in this study have been deposited in the GenBank database under accession numbers KU529484 through KU529566 and KU529567 through KU529649 for ORF28 and ORF36, respectively.

A plaque reduction assay (PRA) was developed in MeWo (melanoma cell line) cell culture for the measurement of the ACV EC 50 (Merck, Lyon, France) and FOS (AstraZeneca, RueilMalmaison, France), following the previously reported guidelines (Harper, 2000). Briefly, MeWo cells were grown to confluence in 24-well culture plates and then infected with VZV isolates. After $1 \mathrm{~h}$ incubation, media containing different concentrations of antiviral compounds were added. Serial dilutions of ACV and FOS were tested, ranging from 5 to $100 \mu \mathrm{M}$ and 20 to $200 \mu \mathrm{M}$, respectively. The cell cultures were incubated for 5 days, then fixed with $10 \%$ formaldehyde, and finally stained with $1 \%$ crystal violet in $70 \%$ ethanol. The number of viral plaques was counted and $\mathrm{EC}_{50}$ s were calculated by the Kärber method. Two distinct ACVresistant VZV mutants were selected in MRC-5 cells treated with increasing concentrations of ACV by serial passages of the laboratory strain Oka (VZV-R1 mutant) and a clinical isolate (VZV-R2 mutant). Both drug-susceptible laboratory strain Oka and ACV-resistant viruses selected in vitro were used as controls to validate this PRA, prior to testing VZV clinical 
isolates. The resistance thresholds were set at $\mathrm{EC}_{50}$ values of $30 \mu \mathrm{M}$ for $\mathrm{ACV}$ and $160 \mu \mathrm{M}$ for FOS as previously reported (Saint-Léger et al., 2001).

In parallel, a previously published method for the evaluation of in vitro phosphorylation activity of HSV recombinant TKs was adapted to VZV recombinant TKs (Burrel et al., 2012). For the construction of wild-type TK plasmid, ORF36 from laboratory strain Oka was amplified by PCR with the following forward and reverse primers, respectively: 5'TGTCGCGATCGCCATGTCAACGGATAAAACCGATGTA-3' ${ }^{\prime}$ and 'GTCGGTTTAAACGGAAGTGTTGTCCTGAACGG-3'. The resulting purified amplicon was cloned into the pFN18A HaloTag ${ }^{\circledR}$ Flexi Vector under control of the T7 RNA polymerase promoter, according to manufacturer's instructions (Promega, Charbonnières-les-Bains, France) prior to transformation into competent E. coli DE3(BL21)pLysS cells (Promega). TK_Oka plasmid was then purified using PureYield plasmid Miniprep System ${ }^{\circledR}$ (Promega) and TK gene sequence was ascertained with the Prism Big Dye Terminator Cycle Sequencing Ready Reaction ${ }^{\circledR}$ kit (Applied Biosystems, Courtaboeuf, France) using the automated sequencer ABI PRISM ${ }^{\mathrm{TM}} 3730$ Genetic Analyzer (Applied Biosystems). Four amino acid changes previously identified and whose roles were confirmed with radioactive or enzymatic methods were used as controls for the in vitro TK functional assay: S179N related to natural polymorphism (Morfin et al., 1999), K25R (Talarico et al., 1993) and W225R (Brunnemann et al., 2015; Sauerbrei et al., 2011) conferring resistance to ACV, and stop codon at residue Y206 resulting in a truncated TK phenotype (Morfin et al., 1999). In addition, G24R change, which was selected in cell culture under bicyclic pyrimidine nucleoside analog (BCNA) pressure (Andrei et al., 2012) and which has not previously been assessed by any radioactive or enzymatic method, was also included in this study. Wild-type TK_Oka plasmid was used as matrix to produce recombinant plasmids harboring the different mutations described above (plasmids named TK_G24R, TK_K25R, TK_S179N, TK_Y206stop, and TK_W225R), 
according to previously described procedures (Burrel et al., 2012). All of the modified forward and reverse primers used for site-directed mutagenesis are available on request to S. Burrel. For in vitro production, theS30 T7 E. coli extract-based cell-free protein expression system (Promega) was used to synthesize recombinant TKs, as described by the manufacturer's instructions. When visualization of synthesized TKs was required, biotinylated lysine was incorporated during the translation process using Transcend ${ }^{\mathrm{TM}}$ tRNA (Promega). Recombinant TKs synthesized in this manner were resolved on a SDS-PAGE gel, transferred onto a nitrocellulose membrane, and subjected to colorimetric detection using streptavidin-alkaline phosphatase, according to the manufacturer's instructions (Promega) (Figure 1). After purification of the TK using the dedicated HaloLink ${ }^{\circledR}$ resin (Promega), as previously described (Burrel et al., 2012), protein yields were measured using the Bradford method in order to normalize the amount of purified TKs used for the phophorylation activity assay. Protocols for testing the ACV phosphorylation activity of the purified recombinant TKs using the ADPGlo ${ }^{\mathrm{TM}}$ Kinase Assay (Promega) were identical to those previously described for HSV (Burrel et al., 2012), except the optimal duration of kinase reaction (60 min) and ACV concentration (1 $\mathrm{mM}$ ) that were determined for this study. For comparative purposes, recombinant TK activities were expressed as percentage of TK_Oka activity arbitrarily set at $100 \%$. Controls were included in each experiment: TK-negative control (i.e., pFN18A vector without TK insert) and recombinant TKs: TK_G24R (tested mutation) and TK_K25R, TK_S179N, TK_Y206stop, and TK_W225R (controls). For each recombinant TK, ACV phosphorylation activity was measured in triplicate and mean values \pm standard deviations were calculated. Statistical analysis was applied to compare the phosphorylation activities of the mutated TKs with those of the reference TK_Oka using the Student's $t$-test. 
Results obtained from genotypic studies showed a low polymorphism of VZV TK and DNA polymerase genes (ORF36 and ORF28, respectively), with an interstrain identity over $99.4 \%$ at both nucleotide and amino acid levels for both genes. Four and 12 amino acid changes were identified in TK and DNA polymerase, respectively, that is $1.2 \%$ and $1.0 \%$ of the total codons of the proteins (Table 2). All of the strains that were studied (Table 3) showed the S288L amino acid change with reference to the Dumas strain, as previously reported (Morfin et al., 1999). Regarding TK, 3 amino acid changes were newly described: A29T, at the Cterminus of the ATP-binding site, and T39I and E249K, located outside the functional or conserved regions of the viral enzyme (Figure 2 and Table 3). For the DNA polymerase, 9 novel amino acid changes distributed outside the conserved functional domains (except A439S) were identified: I3L, L209V, V638I, A822T, E824D, Y934C, G1068N, and L1095M (Table 3). In order to identify potential new natural polymorphisms within TK and DNA polymerase, available VZV clinical isolates harboring known amino acid changes and amino acid changes not previously described in the literature were subjected to the PRA described herein. All tested isolates showed ACV and FOS $\mathrm{EC}_{50}$ s below the resistance cutoff values, confirming the natural polymorphism status for novel identified mutations: A29T (TK), I3L, and V638I (DNA polymerase) (Table 4).

The in vitro TK functional assay showed that all mutated recombinant TKs (TK_G24R, TK_K25R, TK_Y206stop, and TK_W225R), except the one harboring the known natural polymorphism S179N (TK_S179N), induced a significant decrease of recombinant TK activities when compared to reference TK_Oka activity $(\mathrm{p}<0.05)$, indicating that those mutations are likely to be associated with ACV-resistance (Figure 3).

Several strategies to study VZV resistance to antivirals were developed in this work. Novel systems for sequencing the entire TK (ORF36) and DNA polymerase (ORF28) genes 
were designed. Our results obtained from the $84 \mathrm{VZV}$ strains in this study (21 VZV clinical isolates, $62 \mathrm{VZV-positive} \mathrm{clinical} \mathrm{samples,} \mathrm{and} \mathrm{laboratory} \mathrm{strain} \mathrm{Oka)} \mathrm{demonstrated} \mathrm{a} \mathrm{very} \mathrm{low}$ level of variation of ORF36 and ORF28 sequences. These findings are consistent with previous studies, which reported very few natural polymorphisms in TK (Morfin et al., 1999; SaintLéger et al., 2001; Sauerbrei et al., 2011; Talarico et al., 1993) and DNA polymerase (Andrei et al., 2012; Kamiyama et al., 2001; Sauerbrei et al., 2011). In this study, 3 and 9 novel amino acid changes were described in TK and DNA polymerase, respectively (Figure 2 and Table 3). Considering the external localization of residue 29 in the TK ATP-binding site (Figure 2), A29T change might not impact functional activity of TK. However, its role deserved to be clarified. Thus, we decided to develop a novel PRA using MeWo cells to characterize antiviral susceptibility from VZV isolates harboring newly described mutations as A29T in TK and V638I and I3L in DNA polymerase. All tested isolates were susceptible to ACV and FOS, confirming that these mutations are likely considered as natural polymorphisms. It is essential to demonstrate the impact on resistance to antivirals of newly identified mutations, in particular to ACV, widely used in first-intention treatment of VZV infections. However, VZV isolation in cell culture from clinical samples is quite challenging and PRA is labor-intensive (Harper, 2000). For these reasons, rapid genotypic methods such as the one proposed in this work should be preferred for clinical situations of suspected VZV resistance to antivirals. Moreover, functional assays may be used to ascertain the role of unknown mutations located within TK when virus isolation and PRA are not possible. Thus, we chose to adapt a non-radioactive method for the evaluation of VZV TK phosphorylation activity in vitro that we previously developed for HSV (Burrel et al., 2012). Recombinant TKs with previously characterized mutations were used as controls to validate this novel assay. TK_S179N phosphorylation activity observed was slightly greater than TK_Oka activity, suggesting a more efficient ACV phosphorylation activity than the wild-type TK. S179N change was previously proved to be a 
natural polymorphism using a radioactive method (Morfin et al., 1999). Compared to TK_Oka, the phosphorylation activities measured are closed to zero and reduced for TK_K25R and for TK_Y206Stop, respectively. These data are in agreement with previous reported results (Morfin et al., 1999; Talarico et al., 1993). The partial activity of TK_Y206Stop could be related to the conservation of the 2 main TK functional domains (i.e., ATP- and nucleosidebinding sites), although the entire tri-dimensional structure is probably affected. W225R change was reported to be associated with clinical resistance to ACV in a hematopoietic stem cell transplant recipient (Sauerbrei et al., 2011). Indeed, in this latter study, the recovered clinical isolate showed an $\mathrm{EC}_{50}$ above the defined resistance threshold in PRA. Moreover, Brunnemann et al. also proved the association of W225R change with resistance to ACV using both functional enzymatic assay and BAC technology approaches (Brunnemann et al., 2015). Once properly validated, our functional assay was used to characterize the potential involvement of the unpreviously tested G24R change in resistance to ACV. This mutation was previously reported in a VZV strain subjected to selective pressure with BCNA (Andrei et al., 2012). Residue 24 is located within the VZV TK ATP-binding site (Figure 2). Our results revealed a decreased phosphorylation activity of $\mathrm{ACV}$. Changes described in the first conserved region of VZV TK have been related to TK deficient [G24E, (Boivin et al., 1994)] or TK altered [K25R, (Talarico et al., 1993)] profiles. Interestingly, G24R change showed partial ACV phosphorylation activity in our study, whereas the previously reported G24E change was related to a TK deficient profile according to the absence of incorporation in VZV infected cells of TK natural substrate, thymidine, and $\left[{ }^{125} \mathrm{I}\right]$ iododeoxycytidin, a radioactive ACV analogue (Boivin et al., 1994). Although tested TK substrates are different, the variation in TK phosphorylation levels between these 2 assays can be attributed to the difference in structure, polarity, and steric hindrance between arginine and glutamic acid in position 24 of 
TK. For those reasons, G24R and G24E changes could differently impact VZV TK functional activity.

In conclusion, this work describes 3 complementary methodologies that aim at analyzing VZV resistance to antivirals. Novel mutations accounting for natural polymorphism and ACVresistance could be identified, expanding therefore the mutation database of VZV TK and DNA polymerase. These new data may be helpul for the interpretation of VZV genotypic antiviral resistance assays and for the management of antiviral treatments of VZV infections.

\section{Acknowledgements}

This work was supported in part by the Association pour la Recherche sur les Infections Virales (ARIV).

We thank Ghislaine Moreau, Coralie Le Clec'h, Catherine Aimé, Laurence Hermet, Nathalie Hamm and Zaïna Aït-Arkoub for helpful advice and excellent technical assistance. 


\section{References}

Andrei, G., Snoeck, R., 2013. Advances in the treatment of varicella-zoster virus infections. Adv. Pharmacol. San Diego Calif 67, 107-168.

Andrei, G., Topalis, D., Fiten, P., McGuigan, C., Balzarini, J., Opdenakker, G., Snoeck, R., 2012. In vitro-selected drug-resistant varicella-zoster virus mutants in the thymidine kinase and DNA polymerase genes yield novel phenotype-genotype associations and highlight differences between antiherpesvirus drugs. J. Virol. 86, 2641-2652.

Boivin, G., Edelman, C.K., Pedneault, L., Talarico, C.L., Biron, K.K., Balfour, H.H., 1994. Phenotypic and genotypic characterization of acyclovir-resistant varicella-zoster viruses isolated from persons with AIDS. J. Infect. Dis. 170, 68-75.

Brunnemann, A.-K., Bohn-Wippert, K., Zell, R., Henke, A., Walther, M., Braum, O., Maschkowitz, G., Fickenscher, H., Sauerbrei, A., Krumbholz, A., 2015. Drug resistance of clinical varicella-zoster virus strains confirmed by recombinant thymidine kinase expression and by targeted resistance mutagenesis of a cloned wild-type isolate. Antimicrob. Agents Chemother. 59, 2726-2734.

Burrel, S., Bonnafous, P., Hubacek, P., Agut, H., Boutolleau, D., 2012. Impact of novel mutations of herpes simplex virus 1 and 2 thymidine kinases on acyclovir phosphorylation activity. Antiviral Res. 96, 386-390.

Burrel, S., Deback, C., Agut, H., Boutolleau, D., 2010. Genotypic characterization of UL23 thymidine kinase and UL30 DNA polymerase of clinical isolates of herpes simplex virus: natural polymorphism and mutations associated with resistance to antivirals. Antimicrob. Agents Chemother. 54, 4833-4842.

Davison, A.J., Scott, J.E., 1986. The complete DNA sequence of varicella-zoster virus. J. Gen. Virol. 67 ( Pt 9), 1759-1816.

Fillet, A.M., Dumont, B., Caumes, E., Visse, B., Agut, H., Bricaire, F., Huraux, J.M., 1998. Acyclovir-resistant varicella-zoster virus: phenotypic and genetic characterization. J. Med. Virol. 55, 250-254.

Frobert, E., Ooka, T., Cortay, J.-C., Lina, B., Thouvenot, D., Morfin, F., 2007. Resistance of herpes simplex virus type 1 to acyclovir: thymidine kinase gene mutagenesis study. Antiviral Res. 73, 147-150.

Frobert, E., Ooka, T., Cortay, J.C., Lina, B., Thouvenot, D., Morfin, F., 2005. Herpes simplex virus thymidine kinase mutations associated with resistance to acyclovir: a site-directed mutagenesis study. Antimicrob. Agents Chemother. 49, 1055-1059.

Harper, D.R., 2000. Determination of Viral Infectivity: HSV, VZV, and CMV. Methods Mol. Med. 24, 119-127.

Kamiyama, T., Kurokawa, M., Shiraki, K., 2001. Characterization of the DNA polymerase gene of varicella-zoster viruses resistant to acyclovir. J. Gen. Virol. 82, 2761-2765. 
Malartre, N., Boulieu, R., Falah, N., Cortay, J.-C., Lina, B., Morfin, F., Frobert, E., 2012. Effects of mutations on herpes simplex virus 1 thymidine kinase functionality: an in vitro assay based on detection of monophosphate forms of acyclovir and thymidine using HPLC/DAD. Antiviral Res. 95, 224-228.

Morfin, F., Thouvenot, D., De Turenne-Tessier, M., Lina, B., Aymard, M., Ooka, T., 1999. Phenotypic and genetic characterization of thymidine kinase from clinical strains of varicella-zoster virus resistant to acyclovir. Antimicrob. Agents Chemother. 43, 24122416.

Ng, T.I., Shi, Y., Huffaker, H.J., Kati, W., Liu, Y., Chen, C.M., Lin, Z., Maring, C., Kohlbrenner, W.E., Molla, A., 2001. Selection and characterization of varicella-zoster virus variants resistant to (R)-9-[4-hydroxy-2-(hydroxymethy)butyl]guanine. Antimicrob. Agents Chemother. 45, 1629-1636.

Piret, J., Boivin, G., 2014. Antiviral drug resistance in herpesviruses other than cytomegalovirus. Rev. Med. Virol. 24, 186-218.

Sahli, R., Andrei, G., Estrade, C., Snoeck, R., Meylan, P.R., 2000. A rapid phenotypic assay for detection of acyclovir-resistant varicella-zoster virus with mutations in the thymidine kinase open reading frame. Antimicrob. Agents Chemother. 44, 873-878.

Saint-Léger, E., Caumes, E., Breton, G., Douard, D., Saiag, P., Huraux, J.M., Bricaire, F., Agut, H., Fillet, A.M., 2001. Clinical and virologic characterization of acyclovirresistant varicella-zoster viruses isolated from 11 patients with acquired immunodeficiency syndrome. Clin. Infect. Dis. Off. Publ. Infect. Dis. Soc. Am. 33, 2061-2067.

Sauerbrei, A., Taut, J., Zell, R., Wutzler, P., 2011. Resistance testing of clinical varicella-zoster virus strains. Antiviral Res. 90, 242-247.

Sauerbrei, A., Vödisch, S., Bohn, K., Schacke, M., Gronowitz, S., 2013. Screening of herpes simplex virus type 1 isolates for acyclovir resistance using DiviTum ${ }^{\circledR}$ assay. J. Virol. Methods 188, 70-72.

Suzutani, T., Saijo, M., Nagamine, M., Ogasawara, M., Azuma, M., 2000. Rapid phenotypic characterization method for herpes simplex virus and Varicella-Zoster virus thymidine kinases to screen for acyclovir-resistant viral infection. J. Clin. Microbiol. 38, 18391844.

Talarico, C.L., Phelps, W.C., Biron, K.K., 1993. Analysis of the thymidine kinase genes from acyclovir-resistant mutants of varicella-zoster virus isolated from patients with AIDS. J. Virol. 67, 1024-1033.

Visse, B., Dumont, B., Huraux, J.M., Fillet, A.M., 1998. Single amino acid change in DNA polymerase is associated with foscarnet resistance in a varicella-zoster virus strain recovered from a patient with AIDS. J. Infect. Dis. 178 Suppl 1, S55-57. 


\section{Figure legends}

Fig 1. Western blot analysis of recombinant TKs

After translation in bacterial lysate system in the presence of precharged labelled biotinylated lysine tRNA complex, samples were subjected onto SDS-PAGE followed by transfer to a nitrocellulose membrane. Produced TKs, tagged at the C-terminus with the HaloTag ${ }^{\circledR}$, were visualized by colorimetric detection using streptavidin-alkaline phosphatase revelation system at the expected size corresponding to the native protein ( $38 \mathrm{kDa}$ for TK_Oka, TK_G24R, TK_K25R, TK_S179N, and TK_W225R, and $23 \mathrm{kDa}$ for the truncated TK_Y206stop protein) fused to HaloTag ${ }^{\circledR}(\sim 33 \mathrm{kDa})$. TK: thymidine kinase.

Fig 2. Map of mutation identified within VZV TK

Conserved regions are represented by gray boxes. The positions (codon numbers) of these conserved regions are indicated under each box. VZV TK is a 341 amino acid protein, encoded by ORF36, containing two functional domains: an ATP binding site (codons 12-29) and a nucleoside binding site (codons 129-145) (Morfin et al., 1999a). Investigated mutations using the TK functional assay described in this study are underlined.

Fig 3. ACV phosphorylation activities of recombinant VZV TKs

$\mathrm{ACV}$ phosphorylation activities of $\mathrm{VZV}$ recombinant $\mathrm{TKs}$ are shown as the percentage of TK_Oka reference activity (set at 100\%). Percentage of ACV phosphorylation activity is noted for each recombinant TK on the histogram. Error bars represent the standard deviations of the means (ACV phosphorylation activity of each recombinant TK was measured in triplicate). *ACV phosphorylation activity of mutant TK statistically lower than that of corresponding reference TK_Oka $(\mathrm{p}<0.05$, Student's $t$ test $)$. 


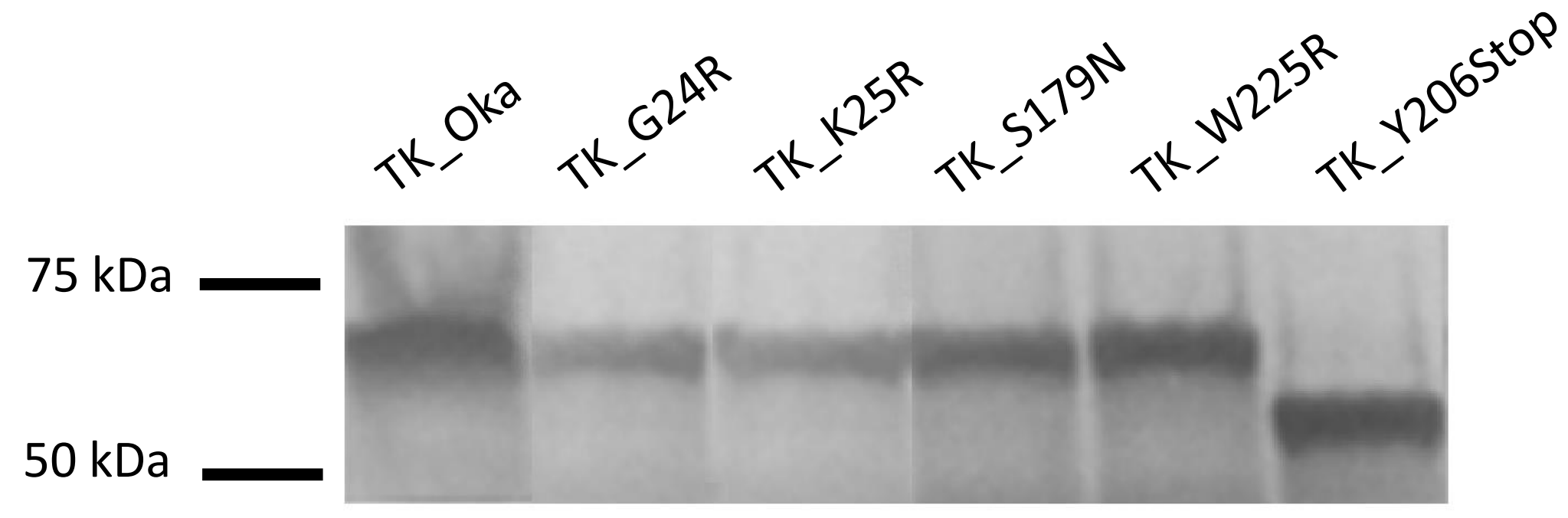

Figure 1. Western blot analysis of recombinant TKs

After translation in bacterial lysate system in the presence of precharged labelled biotinylated lysine tRNA complex, samples were subjected to SDS-PAGE followed by transfer onto a nitrocellulose membrane. Produced TKs, tagged at the C-terminus with the HaloTag ${ }^{\circledR}$, were visualized by colorimetric detection using streptavidinalkaline phosphatase revelation system at the expected size corresponding to the native protein ( 38 kDa [kiloDaltons] for TK_Oka, TK_G24R, TK_K25R, TK_S179N, and TK_W225R, and 23 kDa for the truncated TK_Y206stop protein) fused to HaloTag ${ }^{\circledast}(\sim 33 \mathrm{kDa})$. TK: thymidine kinase. 


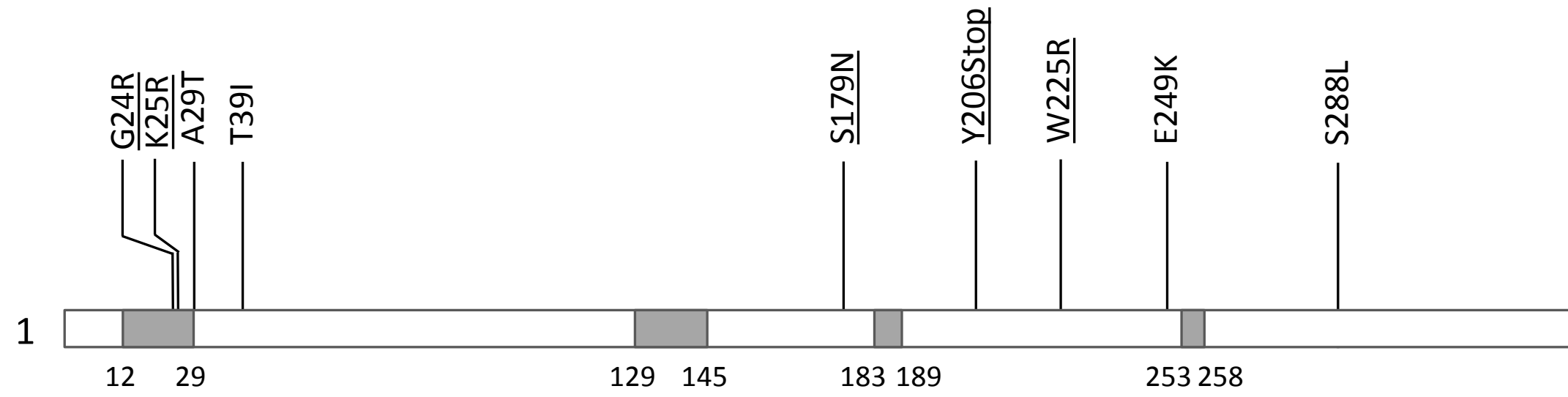

Figure 2. Map of mutations identified within VZV TK

Conserved regions are represented by gray boxes, with the positions (codon numbers) indicated under each box. VZV TK is a 341 amino acid protein, encoded by ORF36, containing two functional domains: an ATP binding site (codons 12-29) and a nucleoside binding site (codons 129-145). Mutations newly described in this study and investigated using the TK functional assay are underlined. 


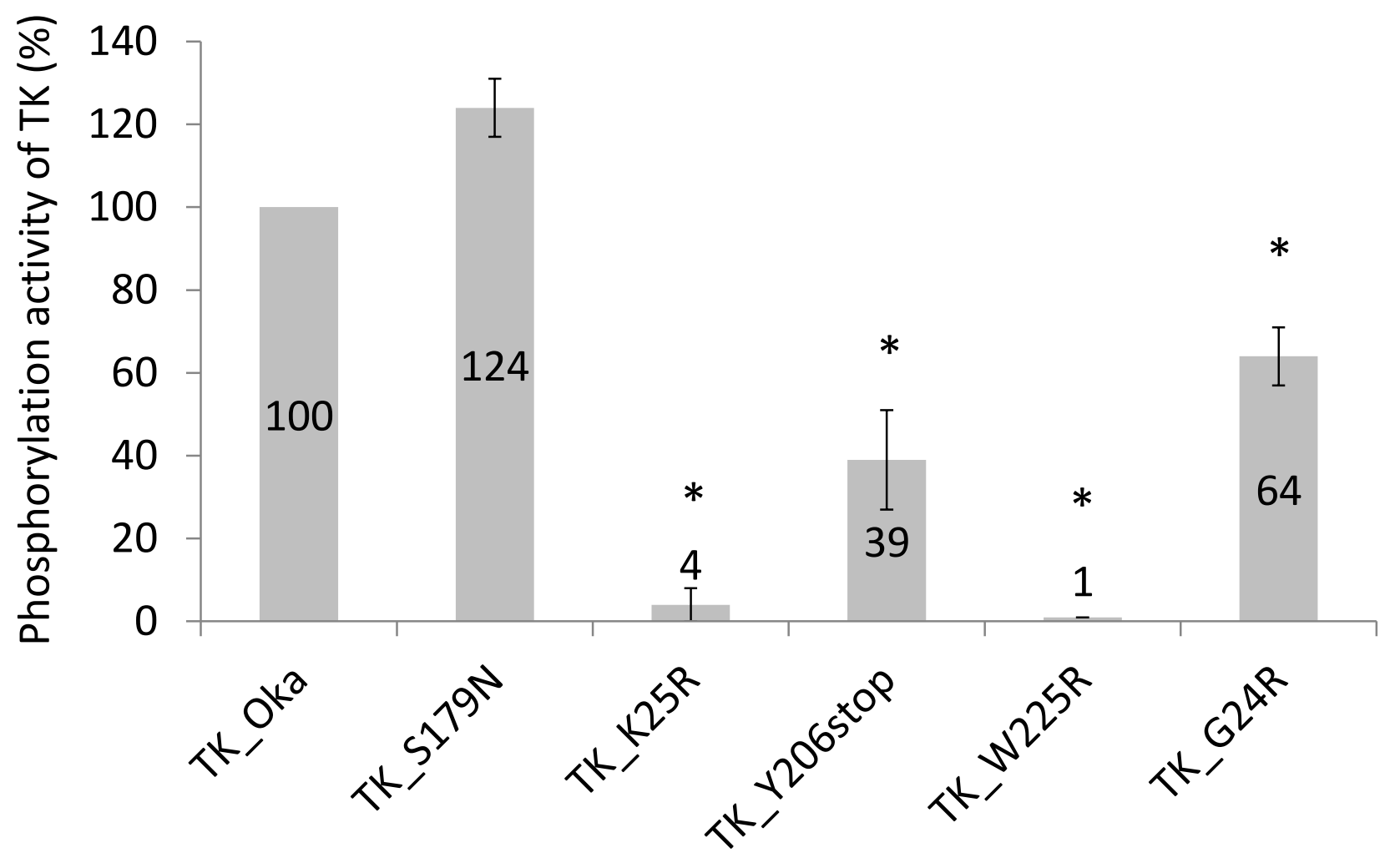

Figure 3. ACV phosphorylation activities of recombinant VZV TKs

ACV phosphorylation activities of VZV recombinant TKs are shown as the percentage of TK_Oka reference activity (set at $100 \%)$. Percentage of ACV phosphorylation activity is noted for each recombinant TK on the histogram. Error bars represent the standard deviations of the means (ACV phosphorylation activity of each recombinant TK was measured in triplicate). *ACV phosphorylation activity of mutant TK statistically lower than that of corresponding reference TK_Oka ( $p<0.05$, Student's $t$ test). 
Table 1 Primers used for amplification and sequence analysis of VZV full-length ORF36 TK and ORF28 DNA polymerase

\begin{tabular}{|c|c|c|c|}
\hline Gene & Function & Name & Sequence $\left(5^{\prime} \rightarrow 3^{\prime}\right)$ \\
\hline ORF36 & $\begin{array}{l}\text { First-round PCR } \\
\text { (outer primers) } \\
\text { Second-round PCR } \\
\text { (inner primers) } \\
\text { Sequence reaction }\end{array}$ & $\begin{array}{l}\text { VZV_TK-F1 } \\
\text { VZV_TK-R1 } \\
\text { VZV_TK-F2 } \\
\text { VZV_TK-R2 } \\
\text { VZV_TK-A } \\
\text { VZV_TK-B } \\
\text { VZV_TK-C } \\
\text { VZV_TK-D } \\
+ \text { VZV_TK-F2/R2 }\end{array}$ & $\begin{array}{l}\text { F: ACAGCCCTTTGAACATCCAC } \\
\text { R: CGCTGTTACTTGCGCTACAA } \\
\text { F: GATAACGGCGACAGGAGTTT } \\
\text { R: AAGGCGGGATTAAAGGATGT } \\
\text { R: TAGTTGAGGCGATTG GGTGT } \\
\text { F: CACCAAACCGGATCTTACTCA } \\
\text { R: CGCGTGCCAGTTGTTAGTT } \\
\text { F: CGGTTAATCTGCCGTTTGTT }\end{array}$ \\
\hline ORF28 & $\begin{array}{l}\begin{array}{l}\text { First-round PCR } \\
\text { (outer primers) }\end{array} \\
\text { Second-round PCR } \\
\text { (inner primers) } \\
\text { Sequence reaction }\end{array}$ & $\begin{array}{l}\text { VZV_POL-F1 } \\
\text { VZV_POL -R1 } \\
\text { VZV_POL-F2 } \\
\text { VZV_POL-R2 } \\
\text { VZV_POL-A } \\
\text { VZV_POL-B } \\
\text { VZV_POL-C } \\
\text { VZV_POL-D } \\
\text { VZV_POL-E } \\
\text { VZV_POL-F } \\
\text { VZV_POL-G } \\
\text { VZV_POL-H } \\
\text { VZV_POL-I } \\
\text { VZV_POL-J } \\
\text { VZV_POL-K } \\
\text { VZV_POL-L } \\
+ \text { VZV_POL-F2/R2 }\end{array}$ & $\begin{array}{l}\text { F: GGGAAATCTGTTCACCTCCA } \\
\text { R: CCAAAACCCAGTCTGTCGAT } \\
\text { F: GCGTGTCGGGGGTATAAAAT } \\
\text { R: TATGCGGAAACCACAACAAA } \\
\text { R: AGACAGGGTCAAATCCCAAA } \\
\text { F: GGATCTCCACGTAGCAAAGC } \\
\text { R: CCCAAAAAGCGTACGAGGTA } \\
\text { F: AGGACAAAACAGAGCCGTTG } \\
\text { R: TATATCGATCCGGTGGTCGT } \\
\text { F: CGTTTTCCTCCAACTGTAAAGG } \\
\text { R: TCAACGGTCTCATATCTCTGGA } \\
\text { F: TCCCGGAATGTCTTTGTAGG } \\
\text { R: AGCGACGTTGAAATTGACTG } \\
\text { F: GATGTGTTGCATCGGGAAAC } \\
\text { R: GACCGCTTGGTACCGTTATT } \\
\text { F: ACTCGCTACCGGAACGTATG }\end{array}$ \\
\hline
\end{tabular}

F: forward; POL: DNA polymerase; R: reverse; TK: thymidine kinase. 
Table 2 Variations of VZV TK and DNA polymerase, both at nucleotide and amino acid levels, among $84 \mathrm{VZV}$ isolates in comparison with reference strain Dumas (GenBank accession number X04370)

\begin{tabular}{|l|l|l|}
\hline & $\begin{array}{l}\text { TK } \\
(\text { ORF36) }\end{array}$ & $\begin{array}{l}\text { POL } \\
\text { (ORF28) }\end{array}$ \\
\hline Nucleotide identity (\%) & $99.8-99.9$ & $99.8-100$ \\
\hline Nucleotide mutations (No.) & 13 & 34 \\
\hline Frequency of nucleotide mutations per strain (median) & $1-2(1)$ & $0-7(1)$ \\
\hline Silent nucleotide mutations (\%) & 69.2 & 64.7 \\
\hline Amino acid identity (\%) & $99.4-99.7$ & $99.7-100$ \\
\hline Amino acid changes (No.) & 4 & 12 \\
\hline Frequency of amino acid changes per strain (median) & $1-2(1)$ & $0-3(0)$ \\
\hline Variation of the total codons of the protein (\%) & 1.2 & 1.0 \\
\hline
\end{tabular}

POL: DNA polymerase; TK: thymidine kinase. 
Table 3 Amino acid changes within TK and DNA polymerase identified among 84 VZV isolates in comparison with reference strain Dumas (GenBank accession number X04370)

\begin{tabular}{|l|l|l|l|}
\hline \multicolumn{2}{|c|}{ TK (ORF36) } & \multicolumn{2}{c|}{ POL (ORF28) } \\
\hline Amino acid changes & No. of isolates (\%) & Amino acid changes & No. of isolates (\%) \\
\hline A29T & $1(1.2)$ & I3L & $2(2.4)$ \\
\hline T39I & $1(1.2)$ & G186C & $7(8.3)$ \\
\hline E249K & $1(1.2)$ & L209V & $1(1.2)$ \\
\hline S288L & $84(100)$ & A439S & $1(1.2)$ \\
\hline & & V638I & $1(1.2)$ \\
\hline & & A822T & $1(1.2)$ \\
\hline & & E824D & $1(1.2)$ \\
\hline & & S863G & $24(28.6)$ \\
\hline & & Y934C & $1(1.2)$ \\
\hline & & G1068N & $1(1.2)$ \\
\hline & & L1095M & $2(2.4)$ \\
\hline & & C1159R & $6(7.1)$ \\
\hline
\end{tabular}

Amino acid changes previously reported as natural polymorphisms are in bold. POL: DNA polymerase; TK: thymidine kinase. 
Table 4 Genotypic and phenotypic characteristics of VZV clinical isolates harboring unpreviously reported amino acid changes in TK or DNA polymerase

\begin{tabular}{|c|c|c|c|c|}
\hline \multirow{2}{*}{ Isolate } & \multicolumn{2}{|c|}{ Amino acid changes } & \multicolumn{2}{c|}{ EC $50(\mu \mathrm{M})$} \\
\cline { 2 - 5 } & TK (ORF36) & POL (ORF28) & ACV & FOS \\
\hline Laboratory strain Oka & S288L & G186C, S863G, C1159R & $7.7 \pm 1.8$ & $39 \pm 9.0$ \\
\hline VZV-R1 & N185Stop & G186C, S863G, C1159R & $>\mathbf{1 0 0}$ & $<66$ \\
\hline VZV-R2 & R143G S288L & S863G & $>\mathbf{1 0 0}$ & $<66$ \\
\hline VZV clinical isolate 1 & S288L, $\underline{\text { A29T }}$ & G186C, S863G, C1159R & 7.7 & $<66$ \\
\hline VZV clinical isolate 2 & S288L & $\underline{\text { I3L }}$ & 6.4 & $<66$ \\
\hline VZV clinical isolate 3 & S288L & $\underline{\text { V638I, S863G }}$ & $<5.0$ & $<66$ \\
\hline
\end{tabular}

ACV: acyclovir; $\mathrm{EC}_{50}$ : effective concentration 50\%; FOS: foscarnet; POL: DNA polymerase;

TK: thymidine kinase. Mutation in bold was previously associated with ACV-resistance (Morfin et al., 1999; Piret and Boivin, 2014; Talarico et al., 1993). Underlined mutations were unpreviously reported. Two distinct ACV-resistant VZV mutants were selected in MRC-5 cells treated with escalating concentrations of ACV by serial passages of the laboratory strain Oka (VZV-R1 mutant) and a clinical isolate (VZV-R2 mutant). 